\title{
FRANCISCO SOTERO DOS REIS E A ESCRITA DAS HISTÓRIAS LITERÁRIAS NO BRASIL
}

\section{SOTERO DOS REIS AND THE WRITING OF LITERARY HISTORIES IN BRAZIL}

\author{
Carlos Augusto de Melo* \\ UFU
}

Resumo: Neste artigo, apresento algumas reflexões em torno do projeto de escrita das histórias literárias no Brasil do qual o maranhense Francisco Sotero dos Reis participou, na década de 1860, ao compor seu pioneiro Curso de literatura portuguesa e brasileira (1866-1873), cuja publicação reuniu, em cinco volumes, 103 lições proferidas nas aulas de Literatura do Instituto de Humanidades em São Luís do Maranhão. Demonstro que, nessa obra, Sotero dos Reis narrou duas histórias da literatura, a de Portugal e a do Brasil, à luz de novos códigos historiográficos, em voga no século XIX, os quais preconizavam as singularidades das nações, a visão orgânica dos períodos literários, as relações entre escritores/obras e contexto histórico, entre outros aspectos. Sob as influências dos métodos franceses, preferiu a leitura e a análise dos textos literários à escrita de resumos biobibliográficos. Por outro lado, percebo que essa conscientização histórica moderna não impediu o maranhense de ainda cultivar aspectos de sua formação clássica, como, por exemplo, o domínio das regras do conhecimento retórico-poético. Aponto, também, para os traços subjetivos da narrativa do professor Sotero dos Reis, marcas da individualidade da atividade do historiador. Vale dizer que adoto, neste artigo, um posicionamento teórico-metodológico com bases bibliográficas, a partir de estudos como os de Maria Eunice Moreira, de Circe Bittencourt, de Roberto Acízelo de Souza, e de outros pesquisadores da área. Por fim, espero que as discussões trazidas aqui para os leitores da revista Muitas Vozes oportunizem a necessária revisão das histórias literárias oitocentistas as quais contribuíram para a formação do pensamento literário brasileiro.

Palavras-chave: História Literária. Moderno. Clássico. Francisco Sotero dos Reis.

\author{
* Professor de \\ Literatura do \\ Instituto de Letras e \\ Linguística (ILEEL) \\ da Universidade \\ Federal de Uberlândia \\ (UFU), na cidade de \\ Uberlândia, Minas \\ Gerais, Brasil. \\ E-mail: carlosaug. \\ melo@ufu.br. Apoio \\ financeiro do CNPq e \\ da Fapemig.
}


such as, for example, the grouping of works in literary genres as a national literary phenomena. This article has a theoretical-methodological position, based on studies such as Maria Eunice Moreira, Circe Bittencourt, Roberto Acízelo de Souza, and other researchers in the area. Finally, I hope that these discussions will allow the necessary revision of the eighteenth-century literary histories.

Keywords: Literary History. Modern. Classic. Sotero dos Reis.

Neste artigo, minha proposta é de refletir sobre a escrita do Curso de literatura portuguesa e brasileira, do professor maranhense Francisco Sotero dos Reis, conhecido como um dos fundadores das histórias literárias no Brasil. Tenho, então, a intenção de analisar a relação desse historiador de literatura com a nova consciência história em voga no século XIX, a qual valorizou as particularidades nacionais, a análise sistemática dos fatos literários, o contexto histórico e a periodização com bases científicas. Além disso, proponho examinar como Sotero dos Reis transitou entre essa perspectiva historiográfica moderna e o pensamento tradicional, sobretudo de supremacia dos códigos retóricos e poéticos, no qual se formou. Nesse sentido, aponto para a possibilidade de que, embora se propusesse à adesão de um método historiográfico moderno, sob a influência francesa, Sotero dos Reis deixou marcas de sua formação clássica na escrita do Curso de literatura. Como muitos historiadores, à época, o maranhense não cumpriu à risca com os pressupostos do historicismo oitocentista, cujo posicionamento foi defender a adoção de um método mais objetivo e científico para o estudo dos fatos literários. Essas reflexões permitem perceber que as histórias literárias oitocentistas foram lugar em que, em constantes tensões, transitaram-se tradição e modernidade, verdadeiro espaço do sincretismo histórico-literário.

Desse modo, estou convencido de que, a partir dessas minhas reflexões, será possível desestabilizar as concepções generalizantes e unificadoras acerca da historiografia literária do Oitocentos, as quais, geralmente, teimam encaixar as histórias literárias apenas no formato da categoria historicista do período, como se os historiadores tivessem aderido facilmente a ela ou não tivessem passado por complexas e intensas transformações epistemológicas e metodológicas. Vou mais além, pois quero acreditar que, apesar da adesão ao método historiográfico moderno, percebe-se em Sotero dos Reis, assim como em todos os historiadores de literatura, a presença da subjetividade na prática de escrita da narrativa histórica, perceptível por meio da escolha do cânone literário, do modo de tratamento das obras, do sentimento lusófilo, entre outros pontos.

Antes de se chegar a essas questões centrais, creio que seja fundamental apresentar o perfil intelectual de Sotero dos Reis, muitas vezes esquecido nos vãos da história e da crítica da literatura, e comentar a respeito de sua contribuição para a formação dos estudos literários no Brasil, principalmente pelo pioneirismo de ter conseguido trazer uma sistemática e coesa narrativa 
histórica, com aspectos didáticos, relativa ao conjunto das produções literárias portuguesas e brasileiras.

Quem foi Sotero dos Reis? O nome de registro é Francisco Sotero dos Reis. Ele nasceu em 1800 no Maranhão, onde viveu até sua morte em 1871. Consta que esse maranhense nunca saiu de sua província, mas conseguiu visibilidade nacional pelas contribuições intelectuais que deu em vida. Em ocasião de seu falecimento, a seção "Notícias do Norte” do Diário do Rio de Janeiro afirma:

Ontem, pelas quatro horas da madrugada, faleceu o erudito professor Francisco Sotero dos Reis o decano dos professores do Maranhão, filólogo ilustre, latinista sem igual no país, gramático sem superior nas duas nações sem que se fala o português. Viveu o ilustre finado cerca de 70 anos, e destes mais de 50 foram aplicados ao ensino da Mocidade e ao jornalismo (...). Nos primeiros anos de sua mocidade subiu à cadeira do magistério da qual só desceu para baixar no tumulo. (NOTÍCIAS, 1871, p. 1).

Como se vê, foi um latinista, filólogo, gramático e professor. Esteve à frente dos partidos políticos mais conservadores, o que lhe fez ter algumas indisposições com intelectuais da província. Fundou e colaborou para diversas revistas e periódicos da época. De reconhecida erudição e purismo de linguagem, teve papel significativo na parte de formação dos estudos gramaticais, filológicos, tradutológicos e literários brasileiros. Sotero dos Reis trabalhou como professor e Inspetor Público no Liceu Maranhense e atuou também em outras instituições de ensino em São Luís do Maranhão, como o Instituto de Humanidades, colégio particular cujo proprietário era seu amigo e parceiro intelectual Pedro Nunes Leal. No livro Casa de Pensão, de Aluísio Azevedo, constatei a curiosa presença de Sotero dos Reis:

Só aos doze anos fez o seu exame de português na aula do Pires. Houve muita formalidade. A congregação era presidida pelo Sotero dos Reis; havia vinte e tantos examinandos.

(...)

Pelo incoerente prisma do sonho, o concurso acadêmico amesquinhava-se às ridículas proporções do exame de primeiras letras. Era a mesma salinha do mestre-escola, a mesma banca de paparaúba manchada de tinta, o mesmo fanhoso Sotero dos Reis presidindo a mesa. (...) (AZEVEDO, 2012, p. 7 e 92).

Essas são as reminiscências de infância da protagonista Amâncio. Os tons ácido e amargo, que revelam o estilo naturalista de Aluísio Azevedo, remetem-se às experiências pouco positivas da personagem no Liceu Maranhense. Em dois momentos, Amâncio menciona o nome de Sotero dos Reis que, pelo que parece, possuía lugar de poder nas decisões tomadas dentro das escolas públicas de São Luís. Essas reminiscências, mesmo que 
negativas, mostram o importante papel educacional que Sotero dos Reis executou para a formação da elite intelectual ludovicense. Da atividade docente, o professor maranhense dedicou-se à escrita de estudos pioneiros dentro da área das Letras. Na década de 1860, elaborou, em seis fascículos, a tradução para a língua portuguesa d'Os comentários de Caio Júlio Cesar, bem como contribuiu com seus estudos filológicos pioneiros acerca da formação da língua e da literatura portuguesa, os quais, nesse mesmo período, apareceram em livro: Postilas de gramática geral, aplicada à língua Portuguesa pela análise dos clássicos (1862) e Gramática Portuguesa, acomodada aos princípios gerais da palavra seguidos de imediata aplicação prática (1866), Curso de literatura portuguesa e brasileira (1866-1873).

Há alguns anos tenho pesquisado a produção intelectual de Francisco Sotero dos Reis. Na busca pela recepção crítica desse escritor maranhense, deparei-me com o interessante comentário que, em abril de 1866, Machado de Assis escreveu na seção Semana Literária do Diário do Rio de Janeiro por ocasião do lançamento do Curso de literatura portuguesa e brasileira. O autor de D. Casmurro disse que:

O Sr. Sotero dos Reis é um dos escritores brasileiros que mais tem estudado a nossa formosa língua; a cadeira do Instituto de Humanidades está bem ocupada pelo ilustre tradutor dos Comentários de Cesar, e dando o exemplo de lecionar deste modo a literatura portuguesa e brasileira, faz ele um grande serviço aos escritores do nosso país. (ASSIS, 1866, p. 2)

Considero essa lúcida observação de Machado de Assis pertinente às reflexões deste meu texto, uma vez que, em resumo, faz entender quais foram as principais contribuições de Sotero dos Reis para a história das Letras brasileiras, quais sejam, a filologia, a tradução e o ensino da história da literatura. Quase um século depois dessa recepção crítica de Machado de Assis, Antônio Candido (1975, p. 354) confirma essa hipótese, dizendo que ele deu “à sua pátria o primeiro livro coerente e pensado de história literária, fundindo e superando o espírito de florilégio, de biografia e de retórica, pela adoção dos métodos de Villemain. Merece, portanto, mais do que lhe tem sido dado.” Não é possível discordar da opinião desses dois críticos. Ainda hoje, reconheço que Sotero dos Reis tem merecido muito "mais do que lhe tem sido dado” (CANDIDO, 1975, p. 354). O “grande serviço” do professor maranhense talvez tenha sido ao ensino de história literária, a partir da escrita de seu antológico Curso de literatura portuguesa e brasileira (18661873). ${ }^{1}$ Tudo indica que a escrita de uma história literária não tenha sido acolhida prontamente. Sotero dos Reis chegou a dizer que esse livro não estava em seus planos e, de início, precisou dominar a "repugnância" de fazê-lo, antes de ser vencido pela insistência de Pedro Nunes Leal, diretor e dono do Instituto de Humanidades que o "animou a empreender um trabalho provavelmente superior às” suas “débeis forças”. (REIS, 2014, p. 41). Nas palavras do professor, eis essa confissão na íntegra:
${ }^{1}$ Essa obra recebeu sua segunda edição recentemente e foi dividida em duas partes: a primeira, intitulada Curso de literatura portuguesa e brasileira: fundamentos teóricos e autores brasileiros (2014), cujo responsável pela organização foi o prof. Roberto Acízelo de Souza (Uerj), traz os textos relativos à fundamentação teórica e aos autores e obras brasileiros. A segunda, Curso de literatura portuguesa e brasileira: autores portugueses (2018), sob minha organização, reúne apenas as partes referentes aos estudos da língua e da literatura portuguesa 
Acrescentarei agora algumas palavras sobre a origem deste livro que me constitui autor de mais uma obra que estava longe de propor-me, e que, por direita razão, dedico ao meu amigo o Sr. Dr. Pedro Nunes Leal, pois, a não ser ele, que instantemente me convidou a ler na cadeira de literatura criada no Instituto de Humanidades, de que é mui digno diretor, vencendo a minha repugnância a fazê-lo, nunca teria certamente existido. Assim, se algum mérito tiver esta obra, que ofereço ao público mais confiado em sua benevolência, que no cabedal das próprias luzes, a ele principalmente deve ser atribuído, que me animou a empreender um trabalho provavelmente superior às minhas débeis forças, mas que tenho me esforçado por desempenhar com a melhor vontade, se não com a suficiência desejável. (REIS, 2014, p. 41-42).

Parece-me que esse revelado repúdio inicial do maranhense dizia respeito ao desafio que se teve de, como historiador da literatura oitocentista, vencer as barreiras das limitadas fontes histórico-literárias disponíveis para empreender a escrita de uma narrativa coerente, sistemática, linear, cronológica e de caráter totalizante acerca do passado literário nacional. Em um período em que foi costumeira a reprodução dos discursos intelectuais prontos, principalmente os dos estrangeiros, como aconteceu com a escrita das apostilas ${ }^{2}$ de retórica e poética, a ausência desse tipo de narrativa explica o sentimento de hesitação e insegurança por parte de Sotero dos Reis que teve de se arriscar a um projeto historiográfico fundador. Foi um escritor consciente de que as "histórias da literatura precisavam ser elaboradas desde a estaca zero, projeto que envolveu a geração romântica e se estendeu até a consolidação da crítica científica praticada por Sílvio Romero (...)”. (ZILBERMAN, 2002, p. 38). No contexto educacional oitocentista, por exemplo, constatou-se evidente carência de material didático; muitos relatórios registraram queixas a respeito da falta de manuais didáticos nas instituições de ensino brasileiras. (BITTENCOURT, 1993). Em um de seus relatórios, o inspetor de Instrução Pública, o também maranhense Gonçalves Dias, confirmou que um “dos defeitos é a falta de compêndios; no interior porque os não há, nas capitais porque não há escolha, ou foi mal feita;” (ALMEIDA, 1989, p. 363). Pelo que me consta, anterior ao Curso de literatura, o único manual de história literária que veio a prelo foi o Curso elementar de literatura nacional (1862), de Cônego Fernandes Pinheiro, colocado, por alguns estudiosos, no patamar da primeira história literária propriamente dita escrita por um brasileiro. $\mathrm{O}$ autor dessa obra estava ciente de seu pioneirismo, uma vez que, envaidecido, declara: “Consola-nos, porém, a persuasão de sermos o primeiro em realizarmos um pensamento que, quando aperfeiçoado, será de alguma vantagem para a juventude.” (PINHEIRO, 1862, p. VII).

Fora dos muros escolares, havia algumas recentes narrativas, as quais propuseram adentrar-se nas veredas das modernas sistematizações, mais completas e ousadas, sobre as produções literárias de Portugal e do Brasil,
${ }^{2}$ Sobre esse assunto, sugiro a leitura de meu artigo: Os Manuais de Retórica e Poética: "Lugares de Memória” no Brasil Oitocentista. Fronteiraz, São Paulo, n. 15, p. 120134, dez. 2015. 
como, por exemplo, foram as de Ferdinand Denis, de Joaquim Norberto e de Ferdinand Wolf. Em visita ao Oitocentos, percebe-se uma verdadeira corrida desenfreada dos intelectuais para se granjear o que realmente seria a "verdadeira” história da literatura nacional, uma vez que, espelhado nas atividades intelectuais dos jovens Estado-nações, como era o Brasil, havia uma "aliança entre história da literatura e a ideologia nacionalistas". (MOREIRA, 2002, p. 123). Desse modo, conforme palavras de Anthony Smith, o nacionalismo necessitava de "una inmersión em la cultura de la nación, el redescubrimiento de su historia, la revitalización de sus lenguas vernáculas a través de disciplinas como la filología y la lexicografia, el cultivo de su literatura (...)”. (SMITH, 2004, p. 21).

Passo, agora, à questão fulcral do artigo: qual foi o método escolhido pelo maranhense para escrita de sua história literária? Vejo que, independentemente daquelas hesitações iniciais, o professor maranhense foi extremamente corajoso em sua estratégia de inovação historiográfica em um período ainda carente de histórias literárias. Percebo que Sotero dos Reis quis ser moderno à luz das novas correntes historicistas europeias. Ele mesmo confirmou esse posicionamento:

Não quero com isto dizer que seja completo o meu trabalho debaixo do ponto de vista em que o concebi; não, não nutro semelhante vaidade; o que apresento é apenas um imperfeito ensaio cuja ideia me foi suscitada pela leitura das obras de alguns modernos literatos franceses; ensaio que pode ser melhorado pelos que podes de mim trilharem a mesma estrada.

A questão é unicamente de método no inspiras amor ao estudo das belas-letras, sem cujo conhecimento não pode haver sólida educação civil e científica. Pode ser que eu esteja enganado, mas parece-me que o método seguido até hoje nos dois países de língua portuguesa não é o mais apropriado ao fim que se tem em vista. (REIS, 2014, p. 41).

Essas observações me chamam bastante a atenção por apresentarem dois pontos importantes que envolveram a escrita das histórias literárias no Brasil do século XIX. O primeiro tem a ver com a consciência do historiador de que, nos primórdios da historiografia, exigiu-se um esforço compartilhado em busca da construção de uma história da literatura que validasse a nacionalidade do país. Apesar de ter, nas entrelinhas do discurso de Sotero dos Reis, uma modéstia retórica, é evidente que, sem embargo, ele esteve consciente de que contribuía decisivamente com a abertura de um novo espaço para a historiografia literária brasileira. Da mesma maneira que Cônego Fernandes Pinheiro (retomando a citação acima na qual ele dizia: "um pensamento que, quando aperfeiçoado [...]") e outros intelectuais da época, Sotero dos Reis teve a percepção da incompletude de uma história literária e de que esse projeto de escrita exigia um complexo work in progress coletivo. Como ressaltou Machado de Assis, escrever as histórias literárias das duas nações, portuguesa e brasileira, era um "trabalho (...) árduo e 
complicado, mas as suas forças dão garantia de bom sucedimento.” (ASSIS, 1866, p. 2). O segundo - e último ponto -, bem demarcado no discurso do professor maranhense, diz respeito à escolha do método certo de historiar literatura, adequando-se apropriadamente "ao fim que se tem em vista”, ou seja, apresentar a unidade do passado literário nacional. Maria Eunice Moreira diz que:

Nascida, assim, sob o signo do historicismo que caracteriza esse momento de ideias, a história da literatura pode ser entendida como um subproduto da história, mas que tem de ser pensada no quadro maior do nascimento da história como ciência. (MOREIRA, 2002, p. 122).

Influenciados pela vertente historicista, os intelectuais brasileiros tentaram adaptar os pressupostos epistemológicos das ciências naturais e exatas à escrita das narrativas históricas que, a partir de uma posição objetiva e analítica do fato literário, sobretudo que o visse dentro de uma linha contínua do tempo histórico, confirmassem a grandiosidade e a unidade da cultura nacional. Sotero dos Reis buscou resolver essa demanda por meio de algumas estratégias que atendessem às vertentes historicistas, como a adoção de uma periodização literária como espelho dos processos históricos nacionais (períodos, séculos, épocas) que se estabelecem na correlação entre literatura e sociedade no decorrer do tempo histórico. A seleção dos escritores e das obras mais representativos relaciona-se com a formação "evolutiva” das duas nações, os quais, de acordo com a vertente positivista, ocorrem em ciclos formativos de "progresso" e "decadência”:

Tenho percorrido na série de preleções até hoje dadas todas as alternativas de progresso e decadência por que tem passado a língua portuguesa desde sua formação provável, em fins do século XII ou princípios do XIII até nossos dias, isto é, por um espaço de cerca de 7 séculos; e é de notar que todas essas alternativas acompanham sempre as de progresso e decadência da literatura, e as desta as de progresso e decadência da nação portuguesa, porque língua, literatura e sociedade política são coisas intimamente ligadas, e uma não decai ou se levanta, sem que a outra decaia ou se levante também. (REIS, 2018, p. 69).

Para além de um mero pioneirismo, essa obra de fôlego, empreendida em resposta à demanda das aulas no Instituto de Humanidades, em São Luís do Maranhão, foi fundamental para, conjuntamente com outros trabalhos ${ }^{3}$ à época, a consolidação de modelos de histórias literárias que se praticaram e, guardadas as devidas proporções, têm-se praticado no Brasil. Ela reuniu algumas das características as quais, desestabilizando a tradicional escrita de compêndios, florilégios e esboços historiográficos, tinham a ver com “o primeiro saber moderno da área” de Letras (SOUZA, 2015, p. 211), ou seja, a história literária, concebida, aqui, como uma narrativa histórica, que, com orientação cronológica concisa, de caráter totalizante e homogeneizante, tem
${ }^{3}$ Refiro-me às histórias literárias que, em meados do século XIX, foram escritas por Joaquim Norberto, Cônego Fernandes Pinheiro e Ferdinand Wolf. Para um panorama sobre esse assunto, sugiro a leitura de Introdução à historiografia da literatura brasileira (Rio de Janeiro: EdUERJ, 2007), de Roberto Acízelo de Souza. 
por objetivo principal possibilitar, por meio de uma percepção científica, a afirmação da literatura nacional.

Sotero dos Reis ficou reconhecido por ser o primeiro brasileiro a propor a escrita de uma história literária na qual fosse reservado um espaço específico para cada uma das duas literaturas (a portuguesa e a brasileira), muito embora reconhecesse os seus complexos vínculos coloniais. Ao contrário do que essa separação pudesse sugerir, o autor não foi de modo algum um nacionalista extremista; longe disso, compartilhava um sentimento lusófilo que defendia a ideia de que a literatura brasileira possuía fortes vínculos culturais que permitiram a consolidação da cultura nacional no Brasil. Concebia um vínculo de parentesco em que se propõe que as duas literaturas sejam "irmãs gêmeas que mal se distinguem por alguma diversidade de forma e ar próprio (...)” (REIS, 2014, p. 61). Para Regina Zilberman, trata-se de uma prática que se pauta "pela constituição de um cânone, o da literatura nacional; mas, para alcançá-lo, era preciso percorrer a trajetória da tradição portuguesa, em que estava enxertada a brasileira.” (ZILBERMAN, 2002, p. 39).

O Curso de literatura, de Sotero dos Reis, é realmente uma obra de fôlego invejável. Percebe-se um erudito professor que buscou, em meio às controversas questões de estabelecimento do Estado-nações, encontrar a melhor maneira de apresentar didaticamente aos seus leitores - e ouvintes, posto que, como material didático, o livro foi lido aos seus alunos nas aulas do Instituto -, a integralidade das culturas literárias, tanto portuguesa quanto brasileira, a partir das novas exigências dos currículos escolares daquele período, os quais cedem espaço ao influente historicismo nacionalista. $\mathrm{O}$ maranhense afirmou que, para a escrita do Curso de literatura, aderiu aos métodos dos “Franceses modernos”, em específico do, nos dias de hoje, também silenciado, professor Abel-Francois Villemain, ${ }^{4}$ cujo método rejeitou a retórica clássica e propôs uma crítica literária moderna que consistiu em uma análise minuciosa, séria e aprofundada “das produções do gênio em cursos especiais, onde tudo quanto respeita à literatura de diversos povos é tratado e exposto com o preciso desenvolvimento.” (REIS, 2014, p. 48). Em sua época, Villemain foi um crítico francês respeitado, tendo sido reconhecido pelas suas inovações críticas, principalmente quando, na década de 1820, adotou-as nas suas preleções sobre a história da literatura francesa que, reunidas em seis volumes, resultaram no Cours de littérature française.

Dessa forma, Sotero dos Reis questionou o fazer historiográfico tradicional, o qual se limitou "quase exclusivamente”, segundo o maranhense, "ao estudo da historia literária e o das produções do gênio em diversas épocas, ou obras dos grandes modelos em poesia, em eloquência, em história, e ainda em ciências (...)”. (REIS, 2014, p. 47). Ele declarou a inviabilidade de se estudar literatura por meio de "compêndios ou resumos de história literária, que apenas nos apresentam um juízo sucinto sobre o mérito em geral de
${ }^{4}$ Abel-Francois Villemain (17901870), político, escritor e professor francês. Foi secretário da Academia Francesa. Lecionou no Lycée Charlemagne e na Sorbonne. Possui uma bibliografia bem extensa.

Além do Cours de littérature, escreveu Essai sur l'oraison funèbre, em Oraisons funèbres de Bossuet, Fléchier et autres orateurs (1837), Études de littérature ancienne et étrangère (1846), Souvenirs contemporains d'histoire et de littérature (1854), Souvenirs contemporains (1856), entre outros estudos. 
cada autor com a data do seu nascimento, ou da época em que floresceu, e a enumeração das obras que compôs”. (REIS, 2014, p. 48). Ancorado nos ensinamentos de Villemain, ele apresentou em seu Curso de literatura essa prática analítica que, ainda não consolidada em terras brasileiras, valorizou a escrita/leitura de "preleções de literatura, dadas em cursos públicos, onde se exponham as belezas e defeitos dos modelos que se oferecem ao nosso estudo, acompanhando-se a análise de cada um deles com a notícia dos fatos mais notáveis de sua vida.” (REIS, 2014, p. 48).

Por outro lado, vislumbro que a escolha de seu método histórico não se resolveu assim tão facilmente aderindo pari passu a essa perspectiva historicista moderna, uma vez que, se considerar a fundo sua proposta metodológica e investigar o tratamento narrativo dado à matéria estudada, percebe-se o trânsito entre os saberes dos consolidados estudos clássicos, sob a égide das disciplinas retórica, poética e filológica, e os dos referidos saberes modernos de inclinações historicistas. A experiência do professor maranhense aconteceu na fronteira tênue e embaçada entre os fundamentos clássicos e os modernos. À proposta moderna de análise e apreciação mais minuciosas dos textos literários em contraposição à concisão dos resumos dos chamados bibliotecas, compêndios, bosquejos e florilégios - gêneros cunhados de "pré-historicistas” por Souza (2015, p. 212) -, conservou-se um saber tradicional e clássico no qual Sotero dos Reis formou-se.

Em seu conjunto, percebo que o Curso de Literatura trouxe marcas da disciplina retórica e poética oriundas de uma formação latinista e purista da qual Sotero Reis se valeu ao longo do tempo. De modo geral, trata-se da reunião das preleções que, originárias da prática oratória do púlpito, eram lidas pelo professor no contexto das aulas de Literatura no Instituto de Humanidades. Essa hipótese se confirma pelo uso constante do verbo ler na primeira pessoa do singular: “Compôs Ferreira dois livros de cartas sobre assuntos literários, morais e filosóficos, das quais vos lerei a XII do livro I dirigida a Diogo Bernardes” (REIS, 2018, p. 186, grifos meus), e pela marcação do vocativo "O poeta com que me vou ocupar hoje, o doutor Antônio Ferreira, pertence já, senhores, ao segundo período literário que me tenho traçado.” (REIS, 2018, p. 175, grifos meus).

O critério analítico do qual Sotero dos Reis se utilizou abarcou leituras de longos trechos das produções literárias, os quais representaram exemplos do cânone literário, escolhido e ensinado aos seus alunos. Após essa prática de leitura, havia a apreciação e o juízo valorativos dos estilos dos autores e obras em conformação às regras dos gêneros literários das disciplinas retórica e poética. Aqueles que não seguiam os preceitos tradicionais não eram bem vistos pelo professor maranhense, sobretudo os que, nas palavras dele, “deformavam” o “aperfeiçoamento” da língua portuguesa, uma vez que "sem perfeito conhecimento da língua, que respeita à literatura que estudamos, nunca poderemos fazer nesta, sólidos progressos.” (REIS, 2018, p. 39). 
Não se pode esquecer que esse posicionamento tem a ver com a tendência de valorização de uma cultura do vernáculo, da pureza, da correção e da elegância da linguagem (ABRANCHES, 1992), que ficou marcada no Grupo Maranhense, do qual Sotero dos Reis foi um dos seus maiores representantes. A bibliografia desse professor não me deixa negar esse fato. Como já tinha dito, escreveu várias gramáticas e, além de tudo, apresentou um minucioso estudo da formação da língua portuguesa, por meio dos textos literários portugueses e brasileiros, nas primeiras preleções do volumoso Curso de literatura. Conhecido pelo seu purismo de linguagem, esse historiador de literatura foi legítimo defensor do aprendizado da língua portuguesa, ou melhor, como dizia sempre, da língua de Camões e de Vieira:

O conhecimento aperfeiçoado da língua deve acompanhar todos os outros, que nunca podem ser cabais sem ele; e admira que o nosso governo, tão solicito em promover entre nós todo e qualquer gênero de conhecimentos humanos, se tenha descuidado deste que é um preliminar indispensável para os mais. O Maranhão felizmente, que a nenhuma outra província do império cede em bons desejos de caminhar para diante nas vias do progresso intelectual, conta dois estabelecimentos disciplinares para o estudo especial da língua, um no Liceu, outro no Instituto de Humanidades, completado pelo atual curso de literatura. (REIS, 2014, p. 42).

Esse olhar rigoroso que vincula língua e literatura ficou evidente na análise dos autores e obras que frequentaram entre os fins do século XVI e parte do século XVII, período considerado por ele a época da decadência da língua e literatura portuguesas, ou nas suas palavras, a "época de degradação intelectual foi fatal à língua e letras pátrias” (REIS, 2018, p. 58). A compreensão de Sotero dos Reis desse período literário esteve relacionada à influência linguística da língua espanhola por ocasião do domínio espanhol na nação portuguesa. Há um verdadeiro repúdio do autor à forma como o estilo literário daquele período - que ficaria conhecido como Gongorismo - influenciou os escritores portugueses. Sotero dos Reis entendeu que:

o homem de talento, que não podia dar largas ao pensamento, nem divagar pelo mundo das ideias, atinha-se à expressão ou às palavras, cujo natural emprego forçava requintando o estilo ou rebicando conceitos triviais por modos mais ou menos engenhosos até a extravagância. Um estilo figurado em que dominam a todo propósito as hipérboles e a metáfora descomunais e mal cabidas, as antíteses reproduzidas até a saciedade, com um cortejo de argúcias e trocadilhos de palavras ou em que nada se diz simples e naturalmente, eis o estilo então em voga! (REIS, 2018, p. 58).

Impressiona-me o esforço desse intelectual em valorizar as competências de escritores que exercitaram estilos literários adequados aos tipos de gêneros literários tradicionais com características linguísticas próprias da língua portuguesa, tendo principalmente como modelo os textos de Camões. 
Colocou em destaque os literatos que, por exemplo, procuraram “não só o termo próprio, mas ainda a expressão mais concisa, animada ou pitoresca. A mesma dificuldade a vencer é parte para que cheguem não poucas vezes à perfeição suma, seja na força do enunciado, seja no colorido da expressão.” (REIS, 2014, p. 49). Essa predileção pelo clássico português é indício dos fortes vínculos de Sotero do Reis com a tradição em um momento de tensas disputas entre gostos lusitanos e antilusitanos:

A luta e a competição foram, de novo, travadas nos bancos escolares: disputavam-se leituras e preferências de gosto, e ainda uma vez consideraram-se indesejados os lusitanos. A vítima da vez foi Camões.

A presença de Camões e dos clássicos portugueses marca a aprendizagem dos escritores, que relembram ora positiva, ora negativamente, a influência sofrida. Assim, às restrições que escritores portugueses inspiravam a alguns autores brasileiros, em virtude de suas manobras pela conquista de gorda fatia do raro mercado disponível para o livro didático, comam-se as carrancudas e não poucas vezes literalmente dolorosas lembranças dos primeiros contatos com as armas e os barões assinalados... (ZILBERMAN, 2002, p. 36, grifos da autora).

Esse vínculo com a formação retórico-poética apareceu também nas estratégias de conformar hierarquicamente as produções literárias aos gêneros literários. Sobretudo, no Curso de literatura, Sotero dos Reis organizou a sua seleção dos escritores de acordo com a sua representatividade nos gêneros prosa e poesia, destacando sempre que este precede àquele:

Na apreciação dos modelos propostos para estudo devem por via de regra ter a primazia os poetas, não só pelo natural atrativo da poesia, que convida a estudá-los, e suaviza o trabalho dos que aprendem, como por sua precedência na ordem cronológica de qualquer literatura, conforme o atesta a história. Em quase todas as línguas, ou antes, em todas elas, os poetas precederam aos prosadores, quer historiadores, quer oradores, quer filósofos, quer de outro gênero; e em quase todas as literaturas foram os poetas os que mais concorreram para o aperfeiçoamento da respectiva língua. (REIS, 2014, p. 49).

Vejo um lugar de primazia histórica que Sotero do Reis ofereceu ao gênero poesia, tendência que, aliás, teve respaldo nas leituras reflexivas de que fez dos textos precursores da poética clássica, aristotélica e horaciana, bem como das produções literárias canônicas escritas pelos poetas, como, por exemplo, Homero, Virgílio, Dante, Ariosto, Tasso. Esses nomes são citados com frequência ao longo do Curso de literatura, como modelos literários a serem seguidos. Em Sotero dos Reis, constata-se uma postura firme de um estudioso que quis comparar os escritores portugueses e brasileiros a esses padrões clássicos. Por exemplo, do ponto de vista do professor maranhense, Camões e Vieira foram quase os únicos escritores que demonstraram competência literária suficiente (rigor de estilo, execução dos gêneros, adorno 
da linguagem, entre outros elementos) para serem equiparados a Homero, a Virgílio e a Horácio.

Quero crer que, por detrás dessa rigidez metodológica, havia um indivíduo, amante de literatura, um leitor, que se emocionava nas leituras das obras e dos autores selecionados em sua prática de escrita historiográfica. Percebo que se registram, no discurso historiográfico de Sotero dos Reis, as subjetividades de historiador no campo da apreciação dos textos literários, fragmentando e esvaziando as possibilidades de um saber histórico imparcial e científico. Nesse sentido, localizo marcas autorais do professor, claras e insubstituíveis, em um movimento de afinidades sensíveis entre historiador e seu objeto literário. Evidenciam-se experiências do historiador da literatura em uma estreita conexão, em linha bastante tênue, entre a identidade coletiva e a individual. Assim como encontro um Sotero dos Reis, intelectual em seu tempo, marcado pelo repertório coletivo de orientações teóricas, políticas e filosóficas nacionalistas, reconheço também aquele Sotero dos Reis que, em sua individualidade, trouxe suas convicções teóricas, seus gostos artísticos, suas práticas leitoras, suas experiências docentes e suas preferências literárias.

Em diversos momentos, demonstrou ser bem subjetivo em suas leituras dos textos literários, abusando do uso de adjetivos, de pontos de exclamação e de certas palavras emotivas, que, de certa maneira, fogem das generalizações objetivas do discurso histórico. Trata-se de um intelectual oitocentista admirador do Belo e do Sublime das Belas-letras. Sotero dos Reis demonstrou com entusiasmo a sua admiração pela "grandiosidade” e "magnitude” dos versos dos poetas e prosadores. Aos escritores preferidos, o maranhense reservou um espaço de elevação e glória literária, evidenciado pelo uso excessivo de superlativos. Ao analisar “Ode ao Estro”, de Francisco Manuel do Nascimento, conhecido pelo pseudônimo Filinto Elísio, a subjetividade do historiador maranhense escancarou-se:

Na primeira das duas odes, tudo, senhores, é grandioso, magnifico, sublime, - o exórdio, a narrativa, a conclusão. Começa o poeta por belíssimos quadros de alguns lugares escolhidos da Ilíada e da Eneida, apresenta depois a soberba pintura dos Lusíadas feita por diversos poetas, segundo a natureza do talento de cada um em relação à das passagens memoradas, e conclui por um discurso posto na boca de Apolo, em que este prediz a Camões a sua celebridade e triste sorte, a que se ligam por incidente as desventuras de Garção e as do mesmo Filinto. Nunca aí arrefece o entusiasmo, nunca falece a fantasia a mais brilhante; as imagens são as mais poéticas; os quadros, os mais pitorescos; o estilo o mais grandíloquo e sublime; a linguagem a mais rica; e em toda a ode reina a bela aparente desordem que se nota em algumas das de Píndaro. (REIS, 2018, p. 621).

Quanto aos versos do português Bocage, Sotero dos Reis, por exemplo, entusiasmou-se ao ponto de simular uma exclamação coletiva bem extasiada 
sobre o poeta, após também algumas considerações de excessiva adjetivação (“animadas”, “primorosas”, “patético”, “divino”):

Esta é de certo uma das pinturas mais animadas, poéticas e primorosas, que jamais se fez em caso análogo, porque nela tudo é patético ou, antes, divino que é o nome que melhor lhe quadra; e tanto que ao lê-la não haverá entendedor que deixe de exclamar extasiado: ah Bocage nasceste poeta! (REIS, 2018, p. 685).

De modo similar, essa subjetividade se revelou à medida que se desenhou o cânone literário na história literária de Sotero dos Reis. Embora sejam cinco longos volumes, o Curso de literatura possui um elenco de escritores pouco numeroso. Comparada a outras histórias literárias, o recorte canônico de Sotero dos Reis é significativamente enxuto. Os portugueses estudados foram Dom Diniz, Bernardim Ribeiro, Gil Vicente, Sá de Miranda, Dom Duarte, Garcia de Resende, Antônio Ferreira, Luís Vaz de Camões, João de Barros, Vasco Mousinho de Quevedo Castelo Branco, Gabriel Pereira de Castro, Frei Luís de Sousa, Jacinto Freire de Andrade, Padre Antônio Vieira, Antônio Diniz da Cruz, Filinto Elísio Manuel Maria Barbosa Du Bocage, Almeida Garret e Alexandre Herculano. Quanto aos brasileiros, os nomes escolhidos para análise foram Santa Rita Durão, Basílio da Gama, Antônio Pereira de Sousa Caldas, Manuel Odorico Mendes, Antônio Gonçalves Dias, Marquês de Maricá, Frei Francisco de Mont’Alverne, Antônio Henriques Leal e João Francisco Lisboa. Desse cânone, chamo atenção para a evidente identificação do historiador da literatura com o seu objeto de estudo. Dos escritores brasileiros, Sotero dos Reis teve uma clara predileção pelos seus conterrâneos Odorico Mendes, Gonçalves Dias, Henriques Leal e Francisco Lisboa. Ou seja, para ele, quase 50 \% do cânone literário brasileiro era maranhense. Além disso, as preferências do maranhense se deixaram ser notadas na ocasião em que se cedeu um generoso espaço das seções a apenas alguns escritores. Enquanto Vasco M. de Q. Castel-Branco e Gabriel Pereira de Castro foram agrupados em uma única seção, Camões possuiu o privilégio de duas específicas, por exemplo. O brasileiro Gonçalves Dias também recebeu essa honraria.

Se os nomes dos escritores passaram por uma seleção bem reduzida, não se pode dizer o mesmo da escolha dos textos literários. Como disse, Sotero dos Reis escreveu uma história literária de fôlego, de cinco volumes, contabilizando mais de 1800 páginas totais. Essa volumosa obra apresentou traços de antologia literária, os quais, no formato didático, traziam textos literários inteiros ou longos fragmentos com os quais se exercitavam a leitura e a análise literária. Leem-se integralmente, por exemplo, muitos dos cantos d'Os Lusíadas, de Camões, e longos e variados trechos das peças teatrais de Gil Vicente. Essa prática antológica já oferece evidências de direcionamentos e intencionalidades autorais, uma vez que forma "em sua grande 
maioria, todos coerentes cuja organização atesta certas atitudes e posturas: face à história e sua relação com a literatura, à autoria, ao julgamento estético.” (ZAMBELLI, 2017, s/p). Trata-se de uma postura bem direcionada aos propósitos particulares do autor que "extrai fragmentos textuais do passado de seus contextos, rearranja-os, oferecendo às gerações presentes e futuras uma visão filtrada e condicionadora do passado, com motivações nem sempre perceptíveis.” (ZAMBELLI, 2017, s/p).

Pincelei algumas ideias aqui sobre a história literária, escrita pelo professor Francisco Sotero dos Reis, as quais apontam para possibilidades de revisitar o passado historiográfico sob outros olhares e novas formas. Da leitura do Curso de literatura, constatei que, dentro de um projeto coletivo de se escrever a história da literatura nacional, localizam-se também domínios individuais de leitura sobre a cultura literária nacional. Os historiadores da literatura oitocentistas precisaram lidar com as transformações do conhecimento e se adequar aos modelos historiográficos para a elaboração dos projetos de histórias literárias. Essa adequação ocorreu em um trânsito mal resolvido entre os saberes tradicionais e modernos, retórico-poéticos e historicistas, lusitanos e antilusitanos. Há de se considerar também que, nessas experiências historiográficas, não se podem negar as motivações pessoais dos historiadores, reveladoras de certa fragmentação do saber histórico e das subjetividades da escrita histórica no século XIX. Termino, então, este texto com a convicção de que, com esses primeiros apontamentos, a revisão das histórias literárias ainda está bem no início e se faz urgente revirar os baús da historiografia literária brasileira.

\section{Referências}

ABRANCHES, Dunshee. O cativeiro. 2. ed. São Luís: ALUMAR, 1992, p. 104.

ALMEIDA, José Ricardo Pires de. História da instrução pública no Brasil (1500-1889). São Paulo: EDUC; Brasília: INEP, 1989.

ASSIS, Machado de. Semana Literária. Diário do Rio de Janeiro, ano XLVI, n. 79, 3 abril de 1866.

AZEVEDO, Aluísio de. Casa de Pensão. Organização de Lisandro Demetrius. Brasília/Rio de Janeiro: Ministério Público/Fundação Biblioteca Nacional, 2012.

BITTENCOURT, Circe M. Fernandes. Livro didático e conhecimento histórico: uma história do saber escolar. 1993 Doutorado) - Faculdade de Filosofia, Letras e Ciências Humanas da Universidade de São Paulo, São Paulo, 1993. 369p.

CANDIDO, Antonio. Formação da literatura brasileira. São Paulo: Martins, 1975. 
MOREIRA, Maria Eunice. História da literatura: algumas considerações teóricas. Vidya: revista eletrônica, v. 21, n. 37, p. 121-129, 2002.

MELO, Carlos Augusto de. Os Manuais de Retórica e Poética: "Lugares de Memória” no Brasil Oitocentista. Fronteiraz, São Paulo, n. 15, p. 120134, dez. 2015.

NOTÍCIAS do norte. Diário do Rio de Janeiro, n. 42, ano 54, p. 1, 11 fev. 1871.

PINHEIRO, Joaquim Caetano Fernandes. Curso elementar de litteratura nacional. Rio de Janeiro: Livraria H. Garnier, 1862.

SMITH, Anthony D. Nacionalismo: teoría, ideología, historia. Tradução deOlaf Bernárdez Cabello, Madrid: Alianza Editorial, 2004.

REIS, Francisco Sotero. Curso de Literatura Portuguesa e Brasileira. Fundamentos teóricos e autores brasileiros. Organização de Roberto Acízelo de Souza, Rio de Janeiro: Caetés, 2014.

- Curso de Literatura Portuguesa e Brasileira: autores portugueses. Organização de Carlos Augusto de Melo. Jundiaí: Paco Editorial, 2018.

SOUZA, Roberto Acízelo de. A ideia de história da literatura. RIHGB. Rio de Janeiro, ano 176 (466), p. 211-220, jan./mar. 2015.

- Introdução à historiografia da literatura brasileira. Rio de Janeiro: EdUERJ, 2007.

ZAMBELLI, Paula Candido. Antologizando a Nação: antologias literárias brasileiras, identidade e ideologia no Estado Novo (1937-1945). Amérique Latine Histoire et Mémoire. Les Cahiers ALHIM [En línea], 33 | 2017, 16 jun. 2017. Disponível em: http://journals.openedition.org/alhim/5718. Acesso em: 12 dez. 2018.

ZILBERMAN, Regina. Literatura portuguesa no Brasil: uma estrangeira entre nós? Vidya: revista eletrônica, v. 21, n. 37, p. 25-41, jan./jun. 2002.

Enviado em agosto/2018.

Aceito dezembro/2018. 